\title{
Emergency use of COVID-19 vaccines recommended by the World Health Organization (WHO) as of June 2021
}

\author{
Xiaoni Cui ${ }^{1}$, Pengxiang Wang ${ }^{1}$, Zhun Wei ${ }^{2, *}$ \\ ${ }^{1}$ Sino-Cell Biomed Co., Ltd., Qingdao, Shandong, China; \\ ${ }^{2}$ Institute of Innovative Drugs and Department of Pharmacology, School of Pharmacy, Qingdao University, Qingdao, Shandong, China.
}

SUMMARY In December 2019, the novel severe acute respiratory syndrome coronavirus 2 (SARS-CoV-2) caused the outbreak of coronavirus disease 2019 (COVID-19), and the resulting pandemic has caused widespread health problems and social and economic disruption. Thus far in 2021, more than 4 million people worldwide have died from COVID-19, so safe and efficacious vaccines are urgently needed to restore normal economic and social activities. According to the official guidance documents of the World Health Organization (WHO), vaccines based on four major strategies including mRNA, adenoviral vectors, inactivated viruses, and recombinant proteins have entered the stage of emergency use authorization and pre-certification evaluation. The current review summarizes these vaccines and it looks ahead to the development of additional COVID-19 vaccines in the future.

Keywords COVID-19, vaccine research, mRNA, adenoviral vectors, inactivated viruses, recombinant proteins

On March 11, 2020, the World Health Organization (WHO) declared novel coronavirus disease 2019 (COVID-19) a global pandemic (1). Severe acute respiratory syndrome coronavirus 2 (SARS-CoV-2), the virus that causes COVID-19, has now infected more than 200 million people and caused more than 4 million deaths. A promising avenue for human beings to overcome epidemics, the research and development of vaccines has been compressed from the usual 10-15 years to 1-2 years as a result of joint efforts worldwide; these efforts are encouraging and fruitful (2). Earlier documents from the WHO described seven platforms or strategies for COVID-19 vaccine development (3). As of June 2021, there are four major categories of vaccines including mRNA vaccines, adenovirusvectored vaccines, inactivated virus vaccines, and recombinant protein vaccines. Vaccines have been produced by 23 businesses and research institutions in 8 countries, leading to the 19 vaccines in the 'emergency use listing/pre-qualification evaluation process' as shown in Table 1 (4).

$m R N A$ vaccines An mRNA vaccine encapsulates the mRNA that encodes the SARS-CoV-2 spike protein (S protein) into lipid nanoparticles, and these nanoparticles are then injected into the human body. After the nanoparticles enter cells, antigen information will be presented on the surface of the cell membrane and an immune response will be induced. Examples of mRNA vaccines are BNT162b2 (produced by Pfizer \&
BioNTech) and mRNA-1273 (produced by Modena). An mRNA vaccine has many advantages such as being noninfectious, being easy to production, and being easy to standardize $(5,0)$. BNT162b2 was granted emergency use authorization by the WHO on December 31, 2020. It is the first mRNA vaccine that was approved for human use. In Israel, more than 6.5 million people over the age of 16 have been vaccinated once BNT162b2 was authorized for emergency use. Its efficacy is as high as $95.3 \%$ within 7 days of 2 rounds of vaccination (7). A study of nearly 4,000 frontline healthcare workers at eight locations in the United States from December 2020 to March 2021 indicated that the rate of infection dropped sharply after 2 rounds of vaccination within 14 days, and vaccine efficacy was $90 \%$ according to the Centers for Disease Control and Prevention (CDC) (8). Another study indicated that neutralizing antibodies and memory B cells remain stable over a period of 6-12 months after BNT162b2 is injected twice. These findings indicate that mRNA vaccines can confer longlasting protection (9) and still remain efficacious against mutants (10).

Adenovirus-vectored vaccines When the S protein gene of SARS-CoV-2 is injected into a nonpathogenic adenovirus, it will express the antigen once it enters the human body, thereby inducing both humoral immunity and cellular immunity. An adenovirus-vectored vaccine should be transported and stored at low temperatures $\left(2-8^{\circ} \mathrm{C}\right)(11)$. Examples of adenovirus-vectored vaccines 
Table 1. Emergency use/pre-certification list of COVID-19 vaccines according to the WHO as of June 2021

\begin{tabular}{|c|c|c|c|}
\hline Platform & Name of Vaccine & Manufacturer & Country \\
\hline mRNA vaccine & $\begin{array}{l}\text { BNT162b2/COMIRNATY Tozinameran (INN) } \\
\text { mRNA-1273 } \\
\text { CVnCoV/CV07050101 }\end{array}$ & $\begin{array}{l}\text { Pfizer \& BioNTech } \\
\text { Moderna } \\
\text { CureVac }\end{array}$ & $\begin{array}{l}\text { USA, Germany } \\
\text { USA } \\
\text { Germany }\end{array}$ \\
\hline $\begin{array}{l}\text { Adenovirus-vectored } \\
\text { vaccine }\end{array}$ & $\begin{array}{l}\text { AZD1222 } \\
\text { Covishield (ChAdOx1_nCoV-19) } \\
\text { Ad26.COV2.S } \\
\text { Sputnik V } \\
\text { Ad5-nCoV }\end{array}$ & $\begin{array}{l}\text { AstraZeneca \& University of Oxford } \\
\text { Serum Institute of India Pvt. Ltd. } \\
\text { Janssen (Johnson \& Johnson) } \\
\text { The Gamaleya National Center } \\
\text { CanSinoBIO }\end{array}$ & $\begin{array}{l}\text { UK } \\
\text { India } \\
\text { USA } \\
\text { Russia } \\
\text { China }\end{array}$ \\
\hline Inactivated vaccine & $\begin{array}{l}\text { SARS-CoV-2 Vaccine (Vero Cell), Inactivated (lnCoV) } \\
\text { CoronaVac } \\
\text { Inactivated SARS-CoV-2 Vaccine (Vero Cell) } \\
\text { COVAXIN } \\
\text { SARS-CoV-2 Vaccine, Inactivated (Vero Cell) }\end{array}$ & $\begin{array}{l}\text { Sinopharm/BIBP } \\
\text { Sinovac } \\
\text { Sinopharm/WIBP } \\
\text { Bharat Biotech } \\
\text { IMBCAMS }\end{array}$ & $\begin{array}{l}\text { China (Beijing) } \\
\text { China } \\
\text { China (Wuhan) } \\
\text { India } \\
\text { China }\end{array}$ \\
\hline $\begin{array}{l}\text { Recombinant protein } \\
\text { vaccine }\end{array}$ & $\begin{array}{l}\text { NVX-CoV2373/Covovax } \\
\text { CoV2 preS dTM-AS03 vaccine } \\
\text { EpiVacCorona } \\
\text { Recombinant Novel Coronavirus Vaccine (CHO Cell) } \\
\text { SCB-2019 } \\
\text { Soberana 01, Soberana 02, Soberana Plus, Abdala }\end{array}$ & $\begin{array}{l}\text { NOVAVAX } \\
\text { Sanofi Pasteur } \\
\text { SRC VB VECTOR } \\
\text { Zhifei Longcom } \\
\text { Clover Biopharmaceuticals } \\
\text { BioCubaFarma }\end{array}$ & $\begin{array}{l}\text { USA } \\
\text { France } \\
\text { Russia } \\
\text { China } \\
\text { China } \\
\text { Cuba }\end{array}$ \\
\hline
\end{tabular}

are AZD1222 (developed by the Jenner Institute of Oxford \& AstraZeneca), Ad26.COV2.S (produced by Johnson \& Johnson), and Ad5-nCoV (produced by CanSinoBIO). Numerous studies involving hundreds of thousands of people in Great Britain have indicated that AZD1222 and BNT162b2 are both effective at preventing infection and severe symptoms of COVID-19 (12-14). A phase 3 trial randomized doubleblind study involving tens of thousands of people has indicated that Ad26.COV2.S was equally effective at preventing infection and at treating severe-critical disease (including hospitalization and death) (15). Data from a phase 3 trial on Sputnik V (developed by the Gamaleya National Center of Epidemiology and Microbiology) will be released later (16,17).

Inactivated vaccines An advantage of an inactivated vaccine is that it retains immunogenicity while lacking the infectivity of a virus. Vaccination with an inactivated virus can stimulate the body to generate a humoral immune response to defend against SARS-CoV-2 (18). The main manufacturers of inactivated vaccines against COVID-19 are Sinopharm/BIBP, Sinovac, and Sinopharm/WIBP. Clinical data indicate that the vaccine produced by Sinopharm/BIBP has an efficacy of $79 \%$ (19). In one study, 13,459 individuals received an initial injection with a vaccine by Sinopharm/WIBP, and 13,066 individuals received the second injection (20). High titers of antibodies developed within 14 days of the second injection, resulting in effective protection, positivity for neutralizing antibodies higher than $99 \%$, and a protective efficacy of $72.8 \%$. The vaccine produced by Sinovac was the second Chinese vaccine approved by the WHO. Although it had an initial efficacy of only $51 \%$, its efficacy at preventing severe illness and mortality was $100 \%$ (19). Inactivated vaccines from Bharat Biotech and the Institute of Medical Biology, Chinese Academy of Medical Sciences (IMBCAMS) have also entered phase III clinical trials or are in development.

Recombinant protein vaccines A target gene (like that encoding a SARS-CoV-2 antigen) is expressed in vitro, transfected into bacteria, yeast, mammal, or insect cells using specific protein vectors, and then the expression of large amounts of antigenic protein is induced under certain conditions. Once the protein is collected and purified, a recombinant protein vaccine can be prepared. There are currently two strategies to prepare recombinant protein vaccines against COVID-19: expression of the $S$ protein and expression of virus-like particles (VLPs). The former ultimately uses purified S protein. An example is NVX-CoV2373/Covovax (produced by NOVAVAX), which was used to vaccinate more than 2,000 volunteers in a phase III clinical trial. Results indicated that the vaccine was $100 \%$ efficacious at preventing moderate to severe disease and that it had an overall efficacy of up to $90.4 \%(21)$. The latter is still being developed and is in the early clinical stage. An example is AS03 (Medicago Inc.), which contains VLPs self-assembled from capsid proteins of SARS-CoV-2 within a heterologous system. VLPs are similar to SARS-CoV-2 since they have its outer shell, but VLPs are hollow since they do not contain the virus' genetic material, so they have no infectivity or replicative capacity. However, VLPs can effectively trigger cellular immunity and humoral immunity $(22,23)$.

In addition to the four main types of vaccines described thus far, several novel manufacturing approaches are being developed. As an example, the diversity and spread of coronaviruses spurred a research team at the Duke University School of Medicine to recently develop several 'mixed' mRNA vaccines with multiple immunogenicity (24). Results from animal trials indicated that these vaccines can target 2-3 different 
coronaviruses at the same time

There are nearly 300 COVID-19 vaccine projects in the research and development stage worldwide, and more than 100 have entered the clinical trial stage (25). More vaccines will appear, and global vaccine production is continually expanding. The resulting vaccines will be able to cover more countries and regions and provide safety and effective protection from this global pandemic.

\section{Funding: None.}

Conflict of Interest: The authors have no conflicts of interest to disclose.

\section{References}

1. WHO Director-General's opening remarks at the media briefing on COVID-19 - 11 March 2020. https://www.who. int/director-general/speeches/detail/who-director-generals-opening-remarks-at-the-media-briefing-on-covid-19--11-march-2020 (accessed March 11, 2021).

2. Huang Q, Yan J. SARS-CoV-2 virus: Vaccines in development. Fundam Res. 2021; 1:131-138.

3. Dai L, Gao GF. Viral targets for vaccines against COVID-19. Nat Rev Immunol. 2021; 21:73-82.

4. Status of COVID-19 Vaccines within WHO EUL/ PQ evaluation process. WHO. https://extranet.who.int/ pqweb/sites/default/files/documents/Status_COVID VAX_16June2021.pdf(accessed June 16, 2021).

5. mRNA vaccines to address the COVID-19 pandemic. https://biontech.de/covid-19-portal/mrna-vaccines (accessed June 16, 2021).

6. Pardi N, Hogan MJ, Porter FW, Weissman D. mRNA vaccines a new era in vaccinology. Nat Rev Drug Discov. 2018; 17:261-279.

7. Haas EJ, Angulo FJ, McLaughlin JM, Anis E, Singer SR, Khan F, Brooks N, Smaja M, Mircus G, Pan K, Southern J, Swerdlow DL, Jodar L, Levy Y, AlroyPreis S. Impact and effectiveness of mRNA BNT162b2 vaccine against SARS-CoV-2 infections and COVID-19 cases, hospitalisations, and deaths following a nationwide vaccination campaign in Israel: an observational study using national surveillance data. Lancet. 2021; 397:18191829.

8. Thompson MG, Burgess JL, Naleway AL, et al. Interim estimates of vaccine effectiveness of BNT162b2 and mRNA-1273 COVID-19 vaccines in preventing SARSCoV-2 infection among health care personnel, first responders, and other essential and frontline workers - Eight U.S. locations, December 2020-March 2021. MMWR. 2021; 70:495-500.

9. Wang Z, Muecksch F, Schaefer-Babajew D, et al. Naturally enhanced neutralizing breadth against SARSCoV-2 one year after infection. Nature. 2021; 595:426431.

10. Liu J, Liu Y, Xia H, Zou J, Weaver SC, Swanson KA, Cai H, Cutler M, Cooper D, Muik A, Jansen KU, Sahin U, Xie X, Dormitzer PR, Shi PY. BNT162b2-elicited neutralization of B.1.617 and other SARS-CoV-2 variants. Nature. 2021; doi: 10.1038/s41586-021-03693-y.

11. Aboul Fotouh K, Cui Z, Williams RO. Next-generation COVID-19 vaccines should take efficiency of distribution into consideration. AAPS PharmSciTech. 2021; 22:126.
12. Bernal JL, Andrews N, Gower C, Robertson C, Stowe J, Tessier E, Simmons R, Cottrell S, Roberts R, O'Doherty M, Brown K, Cameron C, Stockton D, McMenamin J, Ramsay M. Effectiveness of the Pfizer-BioNTech and Oxford-AstraZeneca vaccines on covid-19 related symptoms, hospital admissions, and mortality in older adults in England: test negative case-control study. BMJ. 2021; 373:n1088.

13. Vasileiou E, Simpson CR, Shi T, et al. Interim findings from first-dose mass COVID-19 vaccination roll-out and COVID-19 hospital admissions in Scotland: a national prospective cohort study. Lancet. 2021; 397:1646-1657.

14. Pritchard E, Matthews PC, Stoesser N, et al. Impact of vaccination on new SARS-CoV-2 infections in the United Kingdom. Nat Med. 2021; doi: 10.1038/s41591-02101410-w.

15. Sadoff J, Gray G, Vandebosch A, et al. Safety and efficacy of single-dose Ad26.COV2.S vaccine against Covid-19. N Engl J Med. 2021; 384:2187-2201.

16. Kifle ZD, Enyew EF, Mekuria AB. A recent achievement in the discovery and development of vaccines and therapeutic agents in the race for COVID-19 protection and treatment. J Evid Based Integr Med. 2021; 26:1-10.

17. Mishra SK, Tripathi T. One year update on the COVID-19 pandemic: Where are we now? Acta Trop. 2021; 214:105778.

18. Kandeil A, Mostafa A, Hegazy RR, et al. Immunogenicity and safety of an inactivated SARS-CoV-2 vaccine: Preclinical studies. Vaccines (Basel). 2021; 9:214.

19. Mallapaty S. WHO approval of Chinese CoronaVac COVID vaccine will be crucial to curbing pandemic. Nature. 2021; 594:161-162.

20. Al Kaabi N, Zhang Y, Xia S, et al. Effect of 2 inactivated SARS-CoV-2 vaccines on symptomatic COVID-19 infection in adults: A randomized clinical trial. JAMA. 2021; 326:35-45.

21. Shinde V, Bhikha S, Hoosain Z, et al. Efficacy of the NVX-CoV2373 Covid-19 vaccine against the B.1.351 variant. N Engl J Med. 2021; 384:1899-1909.

22. Brisse M, Vrba SM, Kirk N, Liang Y, Ly H. Emerging concepts and technologies in vaccine development. Front Immunol. 2020; 11:583077.

23. LiY, Tenchov R, Smoot J, Liu C, Watkins S, Zhou Q. A comprehensive review of the global efforts on COVID-19 vaccine development. ACS Cent Sci. 2021; 7:512-533.

24. Martinez DR, Schäfer A, Leist SR, et al. Chimeric spike mRNA vaccines protect against sarbecovirus challenge in mice. bioRxiv. 2021; doi: https://doi. org/10.1101/2021.03.11.434872

25. COVID-19 - Landscape of novel coronavirus candidate vaccine development worldwide. https://www. who. int/publications/m/item/draft-landscape-of-covid-19candidate-vaccines (accessed June22, 2021).

Received July 4, 2021; Revised July 14, 2021; Accepted July $16,2021$.

*Address correspondence to:

Zhun Wei, Institute of Innovative Drugs and Department of Pharmacology, School of Pharmacy, Qingdao University, Qingdao 266003, Shandong, China.

E-mail: biowei@163.com

Released online in J-STAGE as advance publication July 19, 2021. 